\title{
Nanoscale Formulations: Incorporating Curcumin into Combination Strategies for the Treatment of Lung Cancer
}

\author{
Quhui $\mathrm{Wu}^{\prime}$ \\ Huiping Ou' \\ Yan Shang' \\ Xi Zhang' \\ Junyong $\mathrm{Wu}$ (D) $^{2}$ \\ Fuyuan Fan' \\ 'Department of Respiratory Medicine, \\ The First Affiliated Hospital of Hunan \\ University of Chinese Medicine, \\ Changsha, People's Republic of China; \\ ${ }^{2}$ Department of Pharmacy, Second \\ Xiangya Hospital, Central South \\ University, Changsha, 4I00II, People's \\ Republic of China
}

\begin{abstract}
Lung cancer remains the most common cancer worldwide. Although significant advances in screening have been made and early diagnosis strategies and therapeutic regimens have been developed, the overall survival rate remains bleak. Curcumin is extracted from the rhizomes of turmeric and exhibits a wide range of biological activities. In lung cancer, evidence has shown that curcumin can markedly inhibit tumor growth, invasion and metastasis, overcome resistance to therapy, and even eliminate cancer stem cells (CSCs). Herein, the underlying molecular mechanisms of curcumin were summarized by distinct biological processes. To solve the limiting factors that curtail the clinical applications of curcumin, nanoformulations encapsulating curcumin were surveyed in detail. Nanoparticles, including liposomes, micelles, carbon nanotubes (CNTs), solid lipid nanoparticles (SLNs), nanosuspensions, and nanoemulsions, were explored as proper carriers of curcumin. Moreover, it was firmly verified that curcumin has the ability to sensitize lung cancer cells to chemotherapeutic drugs, such as cisplatin and docetaxel, and to various targeted therapies. Regarding the advantages and drawbacks of curcumin, we concluded that combination therapy based on nanoparticles would be the optimal approach to broaden the application of curcumin in the clinic in the near future.
\end{abstract}

Keywords: nanoparticles, curcumin, lung cancer, combination therapy

\section{Introduction}

Lung cancer is the most prevalent cancer worldwide, accounting for $11.6 \%$ of newly diagnosed cancer cases in 2018, and is the leading cause of cancer-related death (18.4\% in 2018). ${ }^{1}$ Despite pronounced advances made in lung cancer screening, early diagnosis and therapy, the 5-year survival rate of lung cancer patients remains low, ranging from $4-17 \%$ depending on the different parameters and regions. ${ }^{2}$ Surgery is recommended for non-small-cell lung cancer (NSCLC) patients with stage I-II disease, and more than $50 \%$ of patients are likely to show favorable results. ${ }^{3}$ However, for most patients, nonsurgical regimens, including chemotherapy, molecular targeted therapy, and immunotherapy, are adopted. Owing to the progress in the molecular understanding of lung cancer, targeted therapy aimed at specific signaling pathways or abnormalities is beneficial for many patients, especially younger patients, who carry corresponding genetic aberrations. ${ }^{4}$ After immunotherapy provided by monoclonal antibodies against PD-1 or PD-L1, one study showed that the 2-year survival rate was approximately $24 \%$ among all enrolled patients. ${ }^{5}$ Although great advances have been made in the treatment of lung cancer, 
relatively low response rates and unfavorable therapeutic endpoints have encouraged researchers to find new therapeutic agents or revised combination regimens.

Curcumin, a natural product from Curcuma longa, has long been used as medicine in China and India. ${ }^{6}$ Curcumin has been exploited to treat numerous diseases, such as inflammatory bowel disease, rheumatoid arthritis, chronic obstructive pulmonary disease, asthma and many cancers, where it exhibits certain efficacy. ${ }^{7-9}$ Curcumin displays high safety in humans and is explicitly efficient in eliminating solid tumors, exemplified by its use against lung cancer, pancreatic cancer, colorectal cancer and so on. ${ }^{10}$ Functionally, the anticancer activity of curcumin is attributed to its antiproliferative, proapoptotic, and proautophagic activities, reducing invasion and metastasis and overcoming drug resistance. The multifaceted roles of curcumin in cancer are mediated by numerous molecular targets, which have been discussed in detail in other reviews. ${ }^{11}$ Regarding the treatment of lung cancer, many signaling pathways and targets are involved, such as cyclin D, BCL-2, STAT3, VEGF, CXCL, and matrix metalloproteinases (MMPs). ${ }^{7-12-14}$ In addition, accumulating evidence indicates that curcumin is sufficient to serve as an adjuvant when combined with other first- or second-line drugs.

However, several drawbacks impede the application of curcumin in the clinic, including its poor aqueous solubility, low bioavailability and rapid metabolism. ${ }^{15}$ To achieve optimal plasma concentrations, up to $2 \mathrm{~g} / \mathrm{kg}, 1 \mathrm{~g} / \mathrm{kg}$ and $12 \mathrm{~g} / \mathrm{kg}$ curcumin should be orally administered to mice, rats, and humans, respectively. ${ }^{16}$ To overcome these obstacles, several strategies have been developed, such as the use of nanoparticles, newly synthesized derivatives, and finding more efficient analogs. ${ }^{17}$ Owing to the many advantages provided by nanoformulations, the emergence of nanotechnology pronouncedly potentiates the feasibility of curcumin in the treatment of cancer. In comparison with free curcumin, encapsulation of this drug into nanoformulations confers high solubility, improved kinetics, reduced adverse events, sustained drug release, and improved targeting ability. ${ }^{18-20}$ Furthermore, nanoparticles are perfect carriers for diverse drugs with distinct characteristics. The most common nanocarriers encapsulating therapeutic drugs include liposomes, polymeric nanoparticles, and inorganic nanoparticles. ${ }^{21}$ Coadministration of curcumin and other therapeutic drugs relying on nanoparticles presents great opportunities to improve efficacy, reduce side effects, and overcome resistance to therapy in lung cancer.

In this review, we first summarized the molecular effects of curcumin against lung cancer sorted by the distinct biological processes. Then, nanoformulations of curcumin were surveyed in detail and sequentially presented according to the different nanocarriers. Furthermore, we discussed the combined strategy of curcumin with chemotherapy and targeted therapy based on nanoparticle systems for the treatment of lung cancer. Finally, we also discussed the challenges of combination therapy involving curcumin relying on nanoparticle technology.

\section{Mechanisms of Curcumin-Mediated Lung Cancer Suppression}

Curcumin possesses multifaceted functions for the treatment of lung cancer, including inhibiting proliferation, promoting apoptosis and autophagy, curbing migration and metastasis, overcoming drug resistance, and eliminating cancer stem cells (CSCs), as illustrated in Figure 1. The molecular mechanisms are summarized in Table 1.

\section{Curcumin Inhibits Proliferation and Promotes Apoptosis and Autophagy in Lung Cancer}

A prominent characteristic of cancer is the limitless proliferation ability. Initial work has shown that curcumin treatment induces a marked improvement in reactive oxygen (ROS) production and a reduction in cell growth in vitro, which was further demonstrated to be mediated by $\mathrm{Wnt} / \beta$-catenin signaling. ${ }^{22}$ Evidence also indicates that curcumin can activate a p53-dependent pathway, leading to the upregulation of several antiproliferative genes and the downregulation of prosurvival genes. ${ }^{23,24}$ In addition, curcumin treatment leads to proliferation arrest and cytotoxic effects via the translocation of Bax and Bad and cytochrome c release in p53-deficient cells. ${ }^{23}$

Apoptosis is an important programmed cell death pathway, and a conclusive linkage between curcumin and apoptosis was strongly confirmed in lung cancer treated with curcumin. In in vivo models, the expression of COX-2, p65 and ERK1/2 decreased and was correlated with impaired tumor growth and survival via apoptosis induction by curcumin. ${ }^{25}$ Multiple lines of evidence suggest that curcumin can modulate a wide range of molecular targets in lung cancer. XIAP, an inhibitor of caspases, is inhibited by curcumin and consequently leads to caspase-3-dependent apoptosis in NSCLC. ${ }^{26}$ Bax and Bad, essential proteins inhibiting apoptosis, were activated by curcumin to promote cell death. ${ }^{27,28}$ In vitro, curcumin was also demonstrated to downregulate PI3K/Akt signaling and enhance 


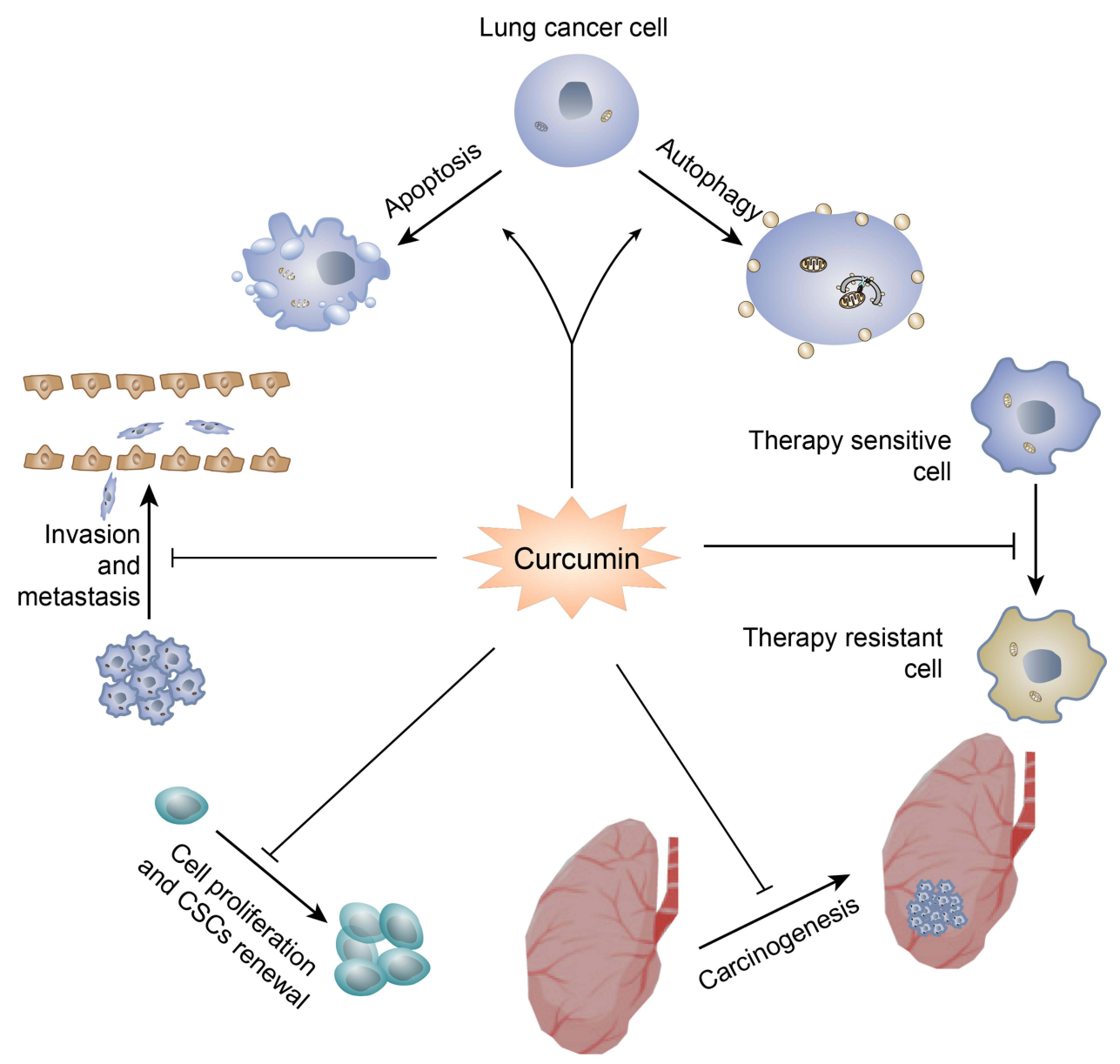

Figure I Schematic of curcumin exerting its effects on lung cancer. Curcumin harbors robust abilities to suppress lung cancer, and the mechanisms include promoting apoptosis and autophagy, inhibiting invasion and metastasis, ameliorating drug resistance, eliminating cancer stem cells (CSCs), and preventing lung carcinogenesis.

antiproliferative effects and apoptosis. ${ }^{29}$ Another suggested signaling pathway, STAT3, which is accompanied by its downstream proteins, including VEGF, Bcl-xL, and cyclin D1, was reduced by curcumin in an in vivo model. ${ }^{30}$ Moreover, anoikis is also involved in curcumin-induced apoptosis through ubiquitin-proteasomal degradation of Bcl-2, which functions as an antiapoptotic protein in various cancer cells. ${ }^{31}$ RNA profiling by a microarray assay suggested that a series of genes associated with DNA damage, the cell cycle and cell growth and cell death were dysregulated after curcumin treatment in lung cancer cells. ${ }^{32}$

Autophagy, an evolutionarily conserved process, maintains intracellular homeostasis by recycling impaired cellular components or organelles. It has also been implicated in drug- or other stimulus-induced effects that lead to cell death, denominated as autophagic cell death. ${ }^{33}$ Enhanced autophagy was observed by intense immunofluorescence staining of LC3 in lung cancer cells treated with curcumin. ${ }^{34}$ GD3 synthase, which is responsible for ganglioside GD3 induction, was further demonstrated to be a transcriptional regulator of autophagy initiation in curcumin-induced autophagy. ${ }^{35}$ In addition, curcumin elevates the phosphorylation of AMPK signaling and facilitates cell death, while inhibition of autophagy by a 3-MA or AMPK special inhibitor alleviates its cytotoxicity in lung cancer cells. ${ }^{34}$ However, most studies concerning the role of autophagy in chemotherapy implicate a protective effect, where enhanced autophagy in response to drugs mitigates cell death, and the results suggesting a prodeath role of autophagy are often derived from cell models with deficient apoptosis. ${ }^{36}$ Thus, the paradox of autophagy in the curcumin-induced response is largely unstudied.

\section{Curcumin Inhibits Invasion and Metastasis}

Invasion, angiogenesis and metastasis are intimately associated with cancer progression, and synergistic inhibition of cell growth and metastasis is beneficial for cancer patients. Mounting evidence suggests that curcumin 
Table I Mechanisms Curcumin Exerts on Lung Cancer

\begin{tabular}{|c|c|c|c|}
\hline Biological Process & $\begin{array}{l}\text { Authors } \\
\text { (Reference) }\end{array}$ & Targeting & Effect \\
\hline Anti-proliferation & $\begin{array}{l}\text { Wang et } \mathrm{al}^{22} \\
\text { Li et } \mathrm{al}^{23}\end{array}$ & $\begin{array}{l}\text { Wnt } / \beta \text {-catenin } \\
\text { p53 }\end{array}$ & $\begin{array}{l}\text { Improvement of ROS production and reduction of cell growth } \\
\text { Upregulation of several antiproliferation genes and } \\
\text { downregulation of prosurvival genes }\end{array}$ \\
\hline Inducing apoptosis & $\begin{array}{l}\text { Lev-Ari et } \mathrm{al}^{25} \\
\text { Ye et } \mathrm{al}^{26} \\
\text { Hai et } \mathrm{al}^{29} \\
\text { Xu et } \mathrm{al}^{30} \\
\text { Pongrakhananon et } \mathrm{al}^{33}\end{array}$ & $\begin{array}{l}\text { COX-2, p65, ERKI/2 } \\
\text { XIAP } \\
\text { PI3K/Akt } \\
\text { STAT3 } \\
\text { Bcl-2 }\end{array}$ & $\begin{array}{l}\text { Impairing tumor growth and inducing apoptosis } \\
\text { Leading to caspase-3-dependent apoptosis } \\
\text { Enhancing antiproliferation effects and apoptosis } \\
\text { Downregulating VEGF, Bcl-xL, and cyclin DI and inducing apoptosis } \\
\text { Inducing anoikis-mediated apoptosis }\end{array}$ \\
\hline Inducing autophagy & $\begin{array}{l}\text { Lee et } \mathrm{al}^{35} \\
\text { Xiao et } \mathrm{al}^{32}\end{array}$ & $\begin{array}{l}\text { GD3 synthase } \\
\text { AMPK }\end{array}$ & $\begin{array}{l}\text { Serving as a transcriptional regulator of autophagy initiation } \\
\text { Inducing autophagic cell death }\end{array}$ \\
\hline $\begin{array}{l}\text { Inhibiting invasion and } \\
\text { metastasis }\end{array}$ & $\begin{array}{l}\text { Chen et } \mathrm{al}^{37} \\
\text { Lu et } \mathrm{al}^{38} \\
\text { Chen et } \mathrm{al}^{39} \\
\text { Chen et } \mathrm{al}^{41} \\
\text { Fan et } \mathrm{al}^{42} \\
\text { Tsai et } \mathrm{al}^{44} \\
\text { Jiao et } \mathrm{al}^{49}\end{array}$ & $\begin{array}{l}\text { HLJI } \\
\text { Metastasis-associated } \\
\text { protein I } \\
\text { Cdc42 } \\
\text { Racl } \\
\text { PKC } \alpha \text {, ATF-2 } \\
\text { NFKB } \\
\text { c-Met }\end{array}$ & $\begin{array}{l}\text { Increasing E-cadherin and inhibiting metastasis } \\
\text { Inhibiting its expression and inactivating Wnt//-catenin pathway } \\
\text { Dysregulating actin cytoskeleton organization } \\
\text { Downregulation of MMP2 and MMP9 } \\
\text { Downregulation of MMP9 } \\
\text { Inhibiting adiponectin expression and metastasis } \\
\text { Blocking PI3K/Akt/mTOR signaling }\end{array}$ \\
\hline $\begin{array}{l}\text { Ameliorating drug } \\
\text { resistance }\end{array}$ & $\begin{array}{l}\text { Zhang et } \mathrm{al}^{54} \\
\text { Kim et } \mathrm{al}^{50} \\
\text { Chen et } \mathrm{al}^{56}\end{array}$ & $\begin{array}{l}\text { miR-I86 } \\
\text { Gas6 } \\
\text { SpI, HDACI }\end{array}$ & $\begin{array}{l}\text { Promoting apoptosis in resistant cells } \\
\text { Inhibiting AxI, P2I, and XIAP, leading to apoptosis } \\
\text { Inducing autophagy-related cell death }\end{array}$ \\
\hline Eliminating CSCs & $\begin{array}{l}\text { Yen et } \mathrm{al}^{59} \\
\text { Mirza et } \mathrm{al}^{60}\end{array}$ & $\begin{array}{l}\text { Wnt/ } \beta \text {-catenin, Hh } \\
\text { JAK2, STAT3 }\end{array}$ & $\begin{array}{l}\text { Leading to proliferation arrest and apoptosis } \\
\text { Inhibiting self-renewal efficacy }\end{array}$ \\
\hline Preventing carcinogenesis & $\begin{array}{l}\text { Puliyappadamba et a }{ }^{61} \\
\text { Moghaddam et } \mathrm{a}^{62}\end{array}$ & $\begin{array}{l}\text { NF- } \mathrm{B}, \mathrm{MAPK} \\
\text { Inflammation } \\
\text { regulators? }\end{array}$ & $\begin{array}{l}\text { Suppressing } \mathrm{B}[\mathrm{a}] \mathrm{PDE} \text {-induced carcinogenesis } \\
\text { Inhibiting intrinsic and extrinsic inflammation and Kras-induced } \\
\text { carcinogenesis }\end{array}$ \\
\hline
\end{tabular}

could efficiently inhibit metastasis at various points of the metastatic cascade, including invasion from the primary site, circulation in blood or lymphatic vessels, extravasation in specific sites, and growth into new lesions. Curcumin exerts antimetastatic effects by targeting a broad range of molecular components.

An initial study revealed that curcumin could activate a tumor suppressor, HLJ1, via upregulation of the JNK/ JunD signaling pathway, resulting in increased E-cadherin expression. ${ }^{37}$ Curcumin inhibits metastasis-associated protein 1 expression, which further inactivates the $\mathrm{Wnt} / \beta$ catenin pathway. ${ }^{38}$ In addition, Cdc42, a Rho GTPase family member, is involved in curcumin-induced antimetastatic effects by regulating actin cytoskeleton organization. ${ }^{39}$ Under curcumin treatment, cytoplasmic stress fibers and membrane filopodia formation were both hampered in lung cancer cells.
Various studies have indicated that curcumin decreases MMP expression and inhibits invasion and metastasis in lung cancer. MMPs, a family of proteases with the ability to breakdown the ECM via collagenase activity, are essential for cancer invasion and progression. ${ }^{40}$ Curcumin treatment leads to the inhibition of Rac1 and downregulation of MMP2 and MMP9. ${ }^{41}$ Another study suggested that the MMP9 content could also be decreased by reducing the activation of PKC $\alpha$ signaling and ATF-2 phosphorylation after curcumin treatment. ${ }^{42}$ Furthermore, MEKK and ERK signaling are inhibited by curcumin, resulting in the downregulation of MMP2 and MMP9 in lung cancer cells. ${ }^{43}$ In addition, inhibition of MMP expression, such as MMP-2 and MMP-9 mediated by NFKB signaling, can regulate adiponectin expression after curcumin treatment. ${ }^{44}$ miRNA microarray analysis indicated that a series of miRNAs associated with invasion and metastasis were 
dysregulated in curcumin-treated lung cancer cells compared with control cells. ${ }^{45,46}$ Thus, a complicated regulatory network of MMP inhibition is deliberately orchestrated in response to curcumin treatment and leads to hampering invasion and metastasis in lung cancer.

In addition to MMP downregulation, curcumin also exerts an influence on epithelial-mesenchymal transition (EMT), which is a pivotal event that generates prometastatic cell types in cancers. ${ }^{47,48}$ It was demonstrated that curcumin inhibits HGF-induced EMT in lung cancer via modulation of c-Met, which functions upstream of PI3K/ Akt/mTOR signaling. ${ }^{49}$ The potential regulatory axis was further verified in HUVECs treated with curcumin, which had impaired tubular formation ability in vitro. However, the opposite conclusion was observed in mice implanted with lung cancer cells: curcumin administration by dietary supplementation did not inhibit metastasis but rather promoted progression, probably by enhancing angiogenesis and inflammation. ${ }^{50}$

\section{Curcumin Ameliorates Drug Resistance in Lung Cancer}

Drug resistance inevitably limits the efficacy of chemotherapy or targeted therapy in lung cancer. Platinum-based chemotherapy, used in combination with gemcitabine, docetaxel or other chemotherapy drugs, results in an overall survival period of 8-10 months in NSCLC patients. ${ }^{51}$ Many patients who are initially sensitive to chemotherapy tend to relapse within six months, and chemotherapy resistance is deemed to be the cause. ${ }^{52}$ Tyrosine kinase inhibitors (TKIs) are a standard of care for patients with epidermal growth factor receptor mutations, while intrinsic resistance conferred by nonsensitizing mutations and secondary resistance conferred by the evolution of cancer cells largely diminishes the clinical effects. $^{53}$ Intriguingly, several studies have shown that curcumin can efficiently overcome drug resistance in lung cancer.

In multidrug-resistant lung adenocarcinoma cells, curcumin downregulates miR-186 and promotes apoptosis. ${ }^{54}$ Similarly, the cytotoxic effects of curcumin on cisplatinresistant and paclitaxel-resistant cells are carried by the Axl protein, which is activated by Gas6 in these resistant cells. $^{55}$ Furthermore, the combination of curcumin and gefitinib, a TKI, significantly inhibits proliferation and colony formation by reducing EGFR phosphorylation through the suppression of $\mathrm{Sp} 1$ activity and its interaction with HADC1 in gefitinib-resistant NSCLC cells. ${ }^{56}$ This report also suggested that combination therapy induces autophagic cell death and apoptosis, contributing to the augmentation of cytotoxic effects and the ability to overcome TKI resistance. These studies unveiled that curcumin is beneficial in mitigating drug resistance in lung cancer and might be an alternative for combination therapy.

\section{Curcumin Eliminates Cancer Stem Cells}

In recent years, increasing evidence has indicated that cancer is highly heterogeneous, consisting of bulk tumor cells, stromal cells, endothelial cells, and a special subtype of cells, cancer stem cells (CSCs). ${ }^{57}$ Accumulating data suggest that CSCs are critically responsible for cancer progression, drug resistance, metastasis and relapse. ${ }^{58}$ Thus, therapeutic regimens targeting CSCs have attracted great attention in pharmacological research.

Initial research has shown that curcumin markedly suppresses lung cancer CSCs, as reflected by impaired tumorsphere formation and the decreased expression of stemness markers such as CD133, CD44 and Nanog. ${ }^{59}$ Regarding the mechanisms, curcumin suppressed the Wnt/ $\beta$-catenin and Hh pathways, which play pivotal roles in stemness maintenance, as they promote tumorsphere formation in vitro and have a striking ability to promote tumorigenicity in vivo. ${ }^{58}$ Similarly, circulating lung cancer CSCs were isolated and treated with curcumin, resulting in significant DNA damage, decreased sphere formation, and cell death via dysregulation of JAK2/STAT3 signaling. ${ }^{60}$ Thus, curcumin has been suggested as an efficient agent for the treatment of CSCs.

\section{Curcumin Prevents Lung Carcinogenesis}

Apart from inhibiting lung cancer in vitro and in vivo, evidence also suggests that curcumin can prevent lung carcinogenesis arising from intrinsic and extrinsic carcinogenic factors. Benzo[a]pyrene, a component of the environment and cigarette smoke, is a carcinogen that leads to DNA adducts and induces mutations via transformation to $\mathrm{B}[\mathrm{a}] \mathrm{PDE}$ in vivo. $^{61}$ Dietary curcumin suppressed $\mathrm{B}[\mathrm{a}]$ PDE-induced carcinogenesis by inhibiting the NF- $\kappa \mathrm{B}$ and MAPK signaling pathways, as indicated by reverted histopathological deviations in mice. ${ }^{61}$ Furthermore, curcumin suppressed the progression of Kras-induced lung cancer in mice by mitigating inflammation. ${ }^{62}$ However, a study found that dietary curcumin did not prevent lung cancer metastasis but rather promoted it; this evidence suggests that curcumin might not be a proper agent for 
carcinogenesis prevention. ${ }^{50}$ Thus, the exact mechanisms by which curcumin prevents lung carcinogenesis should be more thoroughly elucidated in further studies.

Please insert Table 1 here.

\section{Curcumin Formulations Based on Nanoparticles}

Although the versatile role of curcumin in the treatment of lung cancer has been solidly established, the drawbacks of free curcumin delay and weaken its application in clinical situations. Curcumin nanoformulations show great potential in solving these issues and provide proper platforms for combination therapy, which are discussed below.

\section{Liposomal Curcumin}

Liposomes, nanoscale phospholipid bilayer vesicles, have attracted great attention for the delivery of curcumin in various cancer types (Figure 2A), including lung cancer, cervical cancer, prostate cancer, breast cancer and liver cancer. ${ }^{63,64}$ Several key characteristics of liposomes facilitate their use as drug carriers, including low systemic side effects, high biosafety and easy preparation.

Several reports have shown that liposomal curcumin significantly improves the efficiency and safety both in vitro and in vivo compared with free curcumin for the treatment of lung cancer. Zhang et al observed that curcumin liposomes markedly increased cell death compared with free curcumin at $25 \mu \mathrm{M}$, as the cell viabilities were approximately $13.5 \%$ and $38.5 \%$, respectively. ${ }^{65}$ Lin et al reported a cationic liposome-PEG-PEI complex encapsulating curcumin and tested its delivery efficiency and cytotoxic activity in lung cancer cells. ${ }^{66}$ They observed a rapid accumulation of liposomal curcumin in A549 cells over a 2.5 hour incubation period, but no signal from free curcumin appeared even after 4 hours of incubation. Liposomal curcumin markedly arrested the cell cycle and led to apoptosis and also curbed invasion and metastasis. ${ }^{67}$

Since liposomes are convenient and easily captured and metabolized by the reticuloendothelial system, the half-life of these drugs is relatively short. Studies using liposome-based technology have taken these factors into account, and various long-circulating liposomes have been designed and developed, such as PEGylation-modified phospholipids and hyaluronic acid-liposomes. ${ }^{68,69}$ As the cancer cell membrane, which is formed by phosphatidylserines, proteoglycans and other components, is negatively charged, cationic liposomes with positive changes have been conceived to have a greater affinity for the cancer

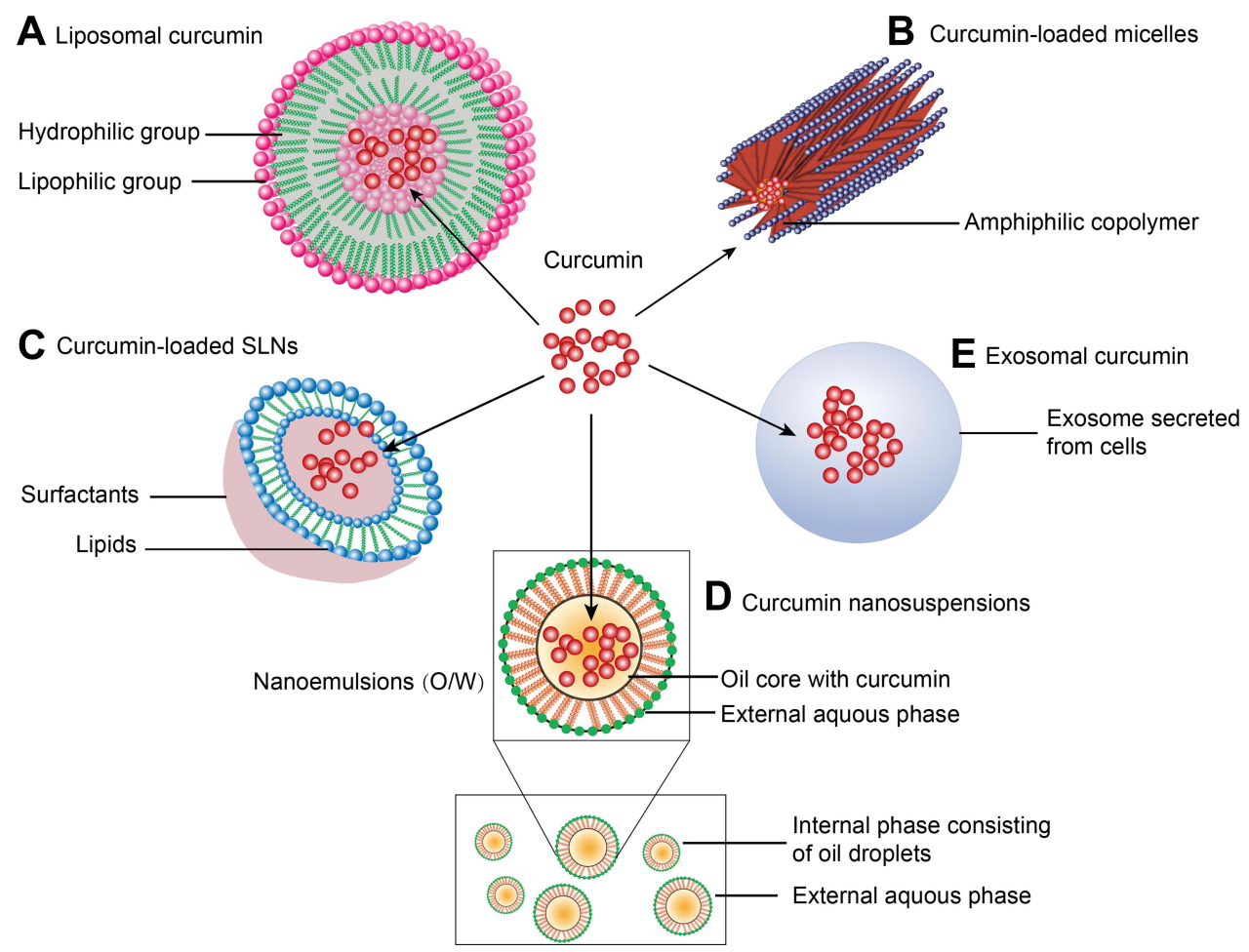

Figure 2 Schematic of nanoscale formulations of curcumin applied for the treatment of lung cancer. (A) Liposomal curcumin; (B) Curcumin-loaded micelles; (C) Curcuminloaded Solid lipid nanoparticles (SLNs); (D) Curcumin nanosuspensions; (E) Exosomal curcumin. 
cell membrane. ${ }^{70,71}$ These advances should pave the way for liposomal curcumin to be applied in the clinic.

\section{Curcumin-Loaded Micelles for Lung Cancer Treatment}

Polymeric micelles have attracted great attention as drug carriers in recent years, showing several advantages, such as easy preparation, drug solubilization, high biocompatibility, good pharmacokinetics, and potential modifications. ${ }^{72}$ Typically, polymeric micelles are spherical particles with sizes less than $100 \mathrm{~nm}$ consisting of hydrophobic blocks, such as polyesters, polyethers and hydrophilic blocks, such as PEG. This biblock (hydrophilic-hydrophobic) structure provides high stability in aqueous solutions and good compatibility for drug loading (Figure 2B).

Self-assembled methoxy polyethylene glycol-polylactide (mPEG-PLA) polymeric micelles, which encapsulate curcumin in the hydrophilic core, have been designed and developed. ${ }^{66}$ Another polymeric micelle derived from Pluronic F, an amphiphilic nonionic polymer mixed with Gelucire $^{@} 44 / 14$, a surface-active lipid excipient used for improving water solubility, was developed and loaded with curcumin. $^{73}$ Transmission electron microscopy images revealed spherical-shaped curcumin-loaded mixed micelles with a rather uniform size distribution. The authors further showed that curcumin-loaded micelles markedly improved cytotoxic effects by approximately 5-fold compared with free curcumin in A549 cells. ${ }^{73}$ In addition, the plasma curcumin concentration after oral administration was measured, and the analysis unveiled a relatively slow and controlled increase of the drug into plasma.

\section{Curcumin-Loaded Carbon Nanotubes (CNTs) in Lung Cancer}

CNTs with several features, including high aspect ratios, large surface areas, rich surface chemical functionalities, and size stability on the nanoscale, have greatly extended exploration and biological applications. ${ }^{74}$ As ALG-coated nanoparticles largely increase loading efficiency and SWNTs with CHI coating release agents faster, dualcoated SWNTs were suspected to be ideal nanoplatforms for drug delivery. ${ }^{75}$ Fiegel et al developed a CNT coating with a small pore (mesoporous) silica and an HSA layer to carry curcumin and camptothecin. ${ }^{76}$ The drug loading capacity of the conjugates was in the range of $0.4-0.7 \%$, which was among the standard values for hydrophobic drug loading using a mesoporous silica system.

In addition, curcumin-loaded SWNTs have shown high solubility and stability. ${ }^{77}$ Modifying the physicochemical parameters of SWNTs by incubation with strong acids, sonication, oxidative modification and noncovalent functionalization conferred a marked enhancement in the biocompatibility of the system. An in vitro study showed enhanced antitumor cell activity of SWNT-curcumin compared with that of free curcumin, as a higher dosedependent and time-dependent increase in efficiency was observed with SWNT-curcumin. This evidence indicates that CNT-curcumin is an efficient delivery system for safely administrating curcumin in vitro, but in vivo results are not available.

\section{Curcumin-Loaded Solid Lipid Nanoparticles (SLNs) in Lung Cancer}

SLNs have several striking advantages compared with other nanosystems, including reduced systemic adverse events due to bypassing the reticuloendothelial system, enhanced biocompatibility, high capability to engulf both hydrophobic and hydrophilic drugs, and high biosafety via lipid biodegradation (Figure 2C). ${ }^{78}$ Baek et al generated and developed multifunctional SLNs for the codelivery of curcumin and paclitaxel. ${ }^{79}$ SLNs loaded with drugs were prepared by emulsification and solvent evaporation, and the encapsulation efficiency was greater than $75 \%$, whereas the folate-modified SLNs showed lower efficiency. The nanoparticle system significantly improved the uptake of paclitaxel and curcumin compared with that of free paclitaxel and curcumin in breast cancer cells, and as predicted, the targeted system further improved the internalization of both drugs.

In a Hodgkin's lymphoma model, SLNs loaded with curcumin significantly increased the level of plasma curcumin and decreased tumor growth by $50.5 \%$ compared with free curcumin, while no adverse events were observed. ${ }^{80}$ In lung cancer, a study systematically investigated the in vitro and in vivo effects of SLN-curcumin. SLN-curcumin led to markedly enhanced cytotoxicity, as the $\mathrm{IC}_{50}$ decreased from $185 \mu \mathrm{M}$ to $32 \mu \mathrm{M}$, although the SLNs also slightly inhibited cell proliferation. ${ }^{81}$ In vivo, SLN-curcumin increased the level of curcumin in plasma, which was attributed to its prolonged release, preventing rapid metabolism and increasing the bioavailability in SLN formulations. Moreover, tissue distribution analyses 
showed that SLN-curcumin improved the concentration of curcumin in the lung and tumor by 32.6- and 4.3-fold compared with that of curcumin. As expected, the SLN formulation significantly inhibited the tumor growth of lung cancer xenografts, whereas no effect was observed in response to curcumin administration alone.

\section{Curcumin Nanosuspensions in Lung Cancer}

Recent advances have demonstrated that nanosuspensions are suitable and efficient for in vitro and in vivo drug delivery owing to their extended surface area and physicochemical properties. ${ }^{82}$ Generally, nanosuspensions are equipped with surfactants or polymeric steric stabilizers, and the specific nanoparticle features allow $100 \%$ drug loading capacity, which assists in researching valid concentrations and minimizing adverse effects. A study reported the feasibility and efficiency of nanosuspensions prepared by precipitation ultrasonication technology for curcumin delivery in vitro and in vivo. ${ }^{83}$ Most of the curcumin was retained in the nanosuspensions after 24 hours of incubation with plasma, and no hemolysis was observed, indicating high safety after intravenous administration.

As the solubility and stability of curcumin are very low in aqueous solution, various stabilizers have been attached to nanosuspensions. A study using $\beta$-lactoglobulin as a stabilizer for curcumin nanosuspensions prepared by the antisolvent precipitation method showed that $\beta$-lactoglobulin markedly modified the morphology of the curcumin nanocrystals, which were more stable in vitro and displayed much higher solubility in vivo than free curcumin. ${ }^{84} \mathrm{~A}$ similar study applied the commercially available stabilizers TPGS and Brij78 to nanosuspensions and suggested that these formulations elevated the bioavailability of curcumin after oral administration. ${ }^{85}$ Collectively, curcumin nanosuspensions significantly improved the aqueous solubility, bioavailability, circulation time and efficiency of curcumin against cancers.

\section{Curcumin Nanoemulsions in Lung Cancer} Nanoemulsions are oil-in-water $(\mathrm{O} / \mathrm{W})$ or water-in-oil (W/ O) dispersions of two immiscible liquids stabilized using an appropriate surfactant. ${ }^{86}$ Nanoemulsions have several features, including high solubilization capacity, great aqueous stability, long-term physical stability, protection of drugs against harsh conditions, avoidance of metabolism by the reticuloendothelial system, and a great capacity to load very hydrophobic drugs. ${ }^{86}$ Accumulating evidence suggests that nanoemulsions could be suitable carriers for loading curcumin (Figure 2D).
Wan et al generated curcumin nanoemulsions by loading water-in-oil nanoemulsions into lipid nanoparticles using a nanoemulsion-film dispersion sonication method and evaluated the release profiles and killing effects in vitro. ${ }^{87}$ This nanoformulation significantly improved the bioavailability, decreased adverse events and led to enhanced efficiency compared with free curcumin in lung cancer. Curcuminoid nanoemulsions prepared by sonication efficiently arrested the cell cycle and promoted apoptosis in lung cancer cells. ${ }^{88}$ Recent evidence suggests that ultrasound-responsive perfluorocarbon nanoemulsions can be properly used as multifunctional smart drug carriers, and this method integrates diagnostic and therapeutic applications. Baghbani et al developed doxorubicin/curcumin codelivery nanoemulsions that displayed increased cytotoxicity to ovarian cancer in vitro and in vivo. ${ }^{89} \mathrm{In}$ addition, biosafe curcumin-loaded nanoemulsions exhibited considerably prolonged release after topical application compared with that of free curcumin and sufficiently suppressed cancer recurrence and metastasis after surgical removal of primary cancers. ${ }^{90}$

\section{Curcumin-Loaded Exosomes in Lung Cancer}

Although nanoparticles based on natural and synthetic lipids possess incredible advantages, some defects, such as their relatively limited retention in circulation and potential toxicity, limit their pharmacological applications. Exosomes are the smallest extracellular vesicles secreted from cells, with sizes ranging from $30-150 \mathrm{~nm} .{ }^{91}$ Recent advances have indicated that exosomes have several advantages over conventional nanoparticles, including high biocompatibility, considerably decreased systemic toxicity, high tissue and biological barrier penetration, and immune supervision evasion. ${ }^{92}$

With regard to loading curcumin, evidence has demonstrated the feasibility and efficiency of exosomes as nanoscale carriers for the treatment of cancers (Figure 2E). Curcumin was loaded into exosomes with an entrapment efficiency of approximately $54 \%$, and the exosomal formulation was stable for more than 6 months at $-80^{\circ} \mathrm{C} .{ }^{93}$ Considerably enhanced curcumin levels were observed in liver and brain tissues compared with tissues after free curcumin treatment, indicating that exosomes improved the bioavailability of curcumin. Exosomal curcumin displayed much higher lung cancer cell killing efficiency and cancer growth inhibition in vivo. Collectively, exosomes might be superior to synthetic carriers for carrying curcumin. 


\section{Combined Strategies Utilizing Nanoparticles to Improve Curcumin Application}

Cumulative preclinical evidence has shown that curcumin could inhibit tumor growth by inducing cell cycle arrest, inhibiting migration and invasion, and inducing pronounced apoptosis in lung cancer. However, currently, no reports have indicated similar effects under clinical conditions. Apart from its limitations of low aqueous solubility and bioavailability, curcumin unfavorably promoted Kras-driven lung tumorigenesis in one study, hampering its application. ${ }^{94}$ Furthermore, poor efficacy was also observed in one preclinical study using solely curcumin for lung cancer treatment (overall efficacy was less than $30 \%$ ). ${ }^{95}$ This evidence indicates that curcumin as a single agent is not suitable for the treatment of cancer. Alternatively, researchers are exploring the potential of curcumin as an adjuvant or combined agent with first-line drugs for the treatment of lung cancer, which are summarized in Table 2 and discussed below.

\section{Synergistic Effects of Curcumin and} Chemotherapy in Lung Cancer

For NSCLC, cisplatin is the first-line therapeutic agent and is recommended for application with other second- or third-line agents. ${ }^{96}$ Compared with cisplatin, the combination of cisplatin and curcumin exhibited an obvious synergistic effect on cytotoxicity and the inhibition of cell viability and colony formation in lung cancer cells. ${ }^{96}$ Mechanistically, p-p38 activation and the expression of $\mathrm{X}$-ray repair cross complementing group 1 (XRCC1), an essential regulator of DNA single-strand break repair, were markedly enhanced by curcumin and cisplatin. The mechanism was further confirmed by the observations that the downregulation of XRCC1 or p-p38 resulted in decreased cell viability in two lung cancer cell lines.

On the other hand, curcumin decreased the level of copper ions and thus promoted the expression of the CTR1 gene, a key copper transporter, through transcriptional activation of Sp1 and CTR1. ${ }^{97}$ Decreased cellular copper ion levels in response to curcumin promoted cisplatin uptake and chemotherapy sensitivity in lung cancer.

Table 2 Synergistic Effects of Curcumin and Chemotherapy or Targeted Therapy in Lung Cancer

\begin{tabular}{|c|c|c|c|}
\hline Drug & $\begin{array}{l}\text { Authors } \\
\text { (Reference) }\end{array}$ & $\begin{array}{l}\text { Combination Mechanism or Nano- } \\
\text { Carrier }\end{array}$ & Effect \\
\hline Cisplatin & Tung et $\mathrm{al}^{96}$ & Activating $\mathrm{p}-38$, downregulating $\mathrm{XRCCl}$ & $\begin{array}{l}\text { Exhibiting synergistic effect on cytotoxicity, cell viability, and } \\
\text { colony formation }\end{array}$ \\
\hline Cisplatin & Zhang et $\mathrm{al}^{97}$ & Inhibiting Cu-SpI-CTRI regulatory loop & $\begin{array}{l}\text { Enhancing apoptosis and inhibited tumor growth in in vitro } \\
\text { and in vivo; killing CSCs }\end{array}$ \\
\hline Cisplatin & Baharuddin et $\mathrm{al}^{98}$ & Inhibiting $\mathrm{p} 2 \mathrm{I}$ and cyclin $\mathrm{DI}$ & Killing CSCs \\
\hline Carboplatin & Kang et al $^{99}$ & Dysregulating caspase- 3 , caspase- 9 and $\mathrm{p} 21$ & $\begin{array}{l}\text { Synergistically inhibiting cell proliferation and induced } \\
\text { apoptosis }\end{array}$ \\
\hline Docetaxel & Yin et al $^{100}$ & Inhibiting cell viability and tumor growth & Satisfying synergistic antitumor efficacy \\
\hline Mitomycin C & Ko et al $^{102}$ & $\begin{array}{l}\text { Downregulating MKKI/2-ERKI/2-mediated } \\
\text { Rad5I expression }\end{array}$ & High efficacy of antitumor effect in vitro model \\
\hline Fenretinide & Chen et $\mathrm{al}^{103}$ & Downregulating GRP78 & Enhancing cytotoxic effects and apoptosis \\
\hline Paris saponin II & Man et al $^{104}$ & Activating the PI3K/AKT, MAPK and NF- $\kappa B$ & Inducing cell cycle arrest and apoptosis \\
\hline Erlotinib & Yamauchi et al ${ }^{108}$ & Inhibiting the activation of $N F \kappa B$ & Enhancing cytotoxicity of erlotinib \\
\hline RTK inhibitors & Lin et $\mathrm{al}^{109}$ & Not presented & Suppressing proliferation in vitro and tumor growth in vivo \\
\hline Doxorubicin & Wang et al ${ }^{111}$ & MPEG-PCL micelles & Better inhibition of lung cancer growth in vivo and in vitro \\
\hline Paclitaxel & Jiang et $\mathrm{al}^{113}$ & RGD-modified liposomes & Better efficacy of antitumor in vivo and in vitro \\
\hline Doxorubicin & Jyoti et al ${ }^{116}$ & Inhalable bioresponsive nanoparticle & Much pronounced cytotoxicity and apoptosis in vitro \\
\hline
\end{tabular}


As expected, the combination of curcumin and cisplatin significantly enhanced apoptosis and inhibited tumor growth in vitro and in vivo. Furthermore, the combined strategy was also beneficial in killing potentially problematic CSCs. Curcumin sensitized lung cancer CSCs to cisplatin by enhancing apoptosis and cell cycle arrest by increasing the expression of several key proteins. $^{98}$ Curcumin combined with carboplatin, another platinum drug widely used in the treatment of lung cancer, also demonstrated a great synergistic effect in lung cancer cells. The results showed that this combination therapy synergistically inhibited cell proliferation and induced apoptosis via dysregulation of caspase-3, caspase- 9 and p21. ${ }^{99}$ Furthermore, combined treatment significantly inhibited cell migration by downregulating MMP-2 and MMP-9. This evidence firmly verified that combination therapy with curcumin and platinum drugs was an effective strategy to eliminate lung cancer cells.

According to National Comprehensive Cancer Network guidelines, docetaxel is preferred in advanced or metastatic lung cancer. To achieve greater antitumor efficacy and reduce adverse events, docetaxel combined with curcumin was exploited. A substantially decreased $\mathrm{IC}_{50}$ was observed, and considerable inhibition of tumor growth was also achieved in the combination group compared with the single treatment groups. ${ }^{100,101}$ Furthermore, combination therapy showed no significant adverse events.

Mitomycin C, a first- or second-line chemotherapy drug for lung cancer, combined with curcumin demonstrated high antitumor efficacy in an in vitro model. ${ }^{102}$ Curcumin potentiated the cytotoxicity of mitomycin $\mathrm{C}$ in two lung cancer cell lines via activation of MKK1/ 2-ERK1/2 signaling, which further suppressed the expression of Rad51, a strand transferase.

Fenretinide, a synthetic retinoid acid (RA), has been suggested as a suitable chemotherapy drug in various studies. ${ }^{103}$ The combination of fenretinide with curcumin led to enhanced cytotoxic effects and apoptosis in lung cancer cells via downregulation of GRP78, a wellrecognized endoplasmic reticulum-chaperone protein. ${ }^{103}$

Another study showed that curcumin could promote the antitumor effects of Paris saponin II (PSII), isolated from Rhizoma Paridis saponins, in lung cancer cells. ${ }^{104}$ They analyzed the proliferation rate, and a combination index of less than 1 was found, showing an obvious synergistic effect between curcumin and PSII in four lung cancer cell lines. The combination treatment promoted the cellular uptake of drugs and induced cell cycle arrest and apoptosis by activating the PI3K/AKT, MAPK and NF- $\mathrm{KB}$ signaling pathways. Similarly, epigallocatechin gallate (EGCG), a natural compound from green tea, showed a higher antiproliferation effect and depressed DNA replication in lung cancer cells and animal models after coadministration with curcumin. ${ }^{105}$

\section{Synergistic Effects of Curcumin and Targeted Drugs in Lung Cancer}

Apart from chemotherapy drugs, studies have also suggested that curcumin can sensitize lung cancer cells to various targeted drugs. Epidermal growth factor receptor tyrosine kinase inhibitors (EGFRs), such as erlotinib, afatinib, and dacomitinib, are the preferred regimens for patients with EGFR mutations. ${ }^{106}$ Although great success has been achieved, primary or acquired resistance still limits the application and efficacy of these drugs in the clinic. ${ }^{107}$ Curcumin inhibited the activation of NFkB by modulating the level of $\mathrm{I} \kappa \mathrm{B}$, which was the underlying mechanism of the enhanced cytotoxicity exerted by erlotinib combined with curcumin in lung cancer cells. ${ }^{108}$ Moreover, combination therapy significantly attenuated tumor growth in vivo, as reflected by tumor volume and histological results. Similar to EGFR inhibitors, other receptor tyrosine kinase (RTK) inhibitors, such as insulinlike growth factor 1 (IGF-1R) and fibroblast growth factor receptor (FGFR) inhibitors, have also been suggested as suitable drugs for combination with curcumin in lung cancer treatment. ${ }^{109}$ Collectively, curcumin robustly sensitizes lung cancer cells to multiple targeted agents.

\section{Combination Therapy Based on Nanoparticles}

It has been firmly verified that curcumin efficiently eliminates lung cancer via multiple pathways that have been suggested to make up a complicated regulatory network and can serve as a largely versatile agent to potentiate responses to conventional chemotherapy or targeted drugs. Strikingly, various studies have indicated that a low dose of curcumin (less than $10 \mu \mathrm{M}$ ) combined with a low dose of chemotherapeutic or targeted drugs led to considerably enhanced cytotoxicity compared to either agent alone. This means that a combination strategy might significantly decrease the required concentration of applied drug while maintaining a robust killing effect on lung cancer. Furthermore, combination therapy led to fewer adverse events and overcame therapy resistance. 
However, a prominent problem that remains is how to achieve the most suitable ratio between different drugs. Drug delivery systems are developed and expected to facilitate drug administration, promote accumulation at the tumor site, reduce adverse events, and maximize killing effects. In recent years, nanoparticle-based delivery systems have advanced considerably, which is attributable to a deep understanding of tumor biology and the availability of biodegradable nanoscale materials. The advantages of a combined strategy based on nanoparticles include better drug solubility, a prolonged circulation period, sustained drug release kinetics, a reduction in adverse events, inhibition of multiple targets and promotion of synergetic effects, as well as the ability to overcome potential resistance. ${ }^{110}$ Several reports have successfully developed these systems to simultaneously carry curcumin and other therapeutic drugs.

Doxorubicin combined with curcumin exhibits high efficacy in suppressing lung cancer, and various nanoparticle systems can sufficiently engulf these two drugs. ${ }^{111,112}$ Wang et al designed and developed a drug delivery system, MPEG-PCL micelles loaded with curcumin and doxorubicin, and examined its antitumor activity in vivo. ${ }^{111}$ The results demonstrated that this formulation inhibited angiogenesis, which was reflected by a defective vascular structure and significantly suppressed tumor growth in vivo compared to single drug treatment. Similarly, nontoxic RGD-modified liposomes were used to encapsulate curcumin and paclitaxel. ${ }^{113}$ The in vitro drug release profile showed sustained release of both drugs in vitro, and enhanced cytotoxicity was also observed. When used at the same concentration, the nanoparticle formulation led to the most obvious inhibition in vivo compared with treatment with the single drugs. Additionally, several overwhelming advantages of inhalation delivery compared to oral and venous administration has driven researchers to investigate whether coloading nanoparticles would be suitable for the treatment of lung cancer. A nanoformulation containing curcumin and methotrexate led to significant cell growth arrest and apoptosis in lung cancer cells. ${ }^{114}$ A coencapsulated nanosystem carrying curcumin and cisplatin exhibited greatly enhanced in vitro and in vivo antitumor effects against lung cancer. ${ }^{115}$ Jyoti et al prepared inhalable bioresponsive nanoparticles carrying doxorubicin and curcumin that efficiently released drugs after being triggered by enzymolysis. ${ }^{116}$ This complex synergistically induced pronounced cytotoxicity and apoptosis in lung cancer cells. This evidence indicates that combination therapy involving curcumin based on nanoparticles is promising to eliminate lung cancer.

\section{Conclusions}

We systematically summarized and discussed the evidence concerning curcumin application in lung cancer. As presented above, curcumin sufficiently inhibits lung cancer proliferation, induces apoptosis and autophagy, inhibits migration and invasion, overcomes drug resistance, eliminates CSCs, and prevents carcinogenesis. These effects are mediated by multiple signaling pathways and a complicated regulatory network. On the other hand, nanotechnology is beneficial to solve the drawbacks that limit the clinical applications of curcumin. Extensive exploitation strategies have been undertaken to incorporate curcumin within various nanoparticles, and antitumor activity has been examined via cultured cells or limited animal models. Combination therapy where curcumin serves as an adjuvant drug loaded into nanoparticles might potentiate the application of curcumin in the clinic.

However, caution should be taken when selecting drugs for combination therapy with curcumin. Many preclinical reports found very interesting mechanisms underlying combination therapy involving curcumin, while very limited clinical evidence or high-grade animal studies were available. This dilemma elicits a vital issue regarding how the reliability of those conclusions are derived from the cultured cell-based design. ${ }^{117,118}$ Furthermore, the combination efficacy can be markedly compromised if an antagonistic regulatory pathway exists among the drugs to antagonize the effects and facilitate cancer development. ${ }^{119}$ Thus, the prominent mechanism of action of curcumin and its partner agent should be explored and summarized in detail.

Challenges in designing effective combination therapy systems for lung cancer also exist. First, it is essential to provide an optimal concentration ratio of each drug encapsulated in the nanoscale system according to pharmacokinetics data and maximum efficacy. ${ }^{120}$ Second, targeting systems armed by specific response factors, such $\mathrm{pH}$ responsive, ROS responsive, or enzyme-mediated elements, are helpful for differentiating between tumor cells and nontumor cells or for differentiating between extracellular and intracellular targets. ${ }^{121}$ Third, the adverse effects of nanoparticles should be carefully surveyed. ${ }^{122}$ In addition, optimized delivery systems highly rely on the entrapped drugs where proper modifications of the nanoparticles are certainly beneficial. Finally, it is crucial to 
develop ligand-conjugated nanosized delivery systems that actively target receptors specifically expressed in cancer cells; in response, due to the overwhelming accumulation in tumor sites, this strategy is speculated to outperform the passive targeting strategy. ${ }^{21,123,124}$

Thus, significant efforts are needed to fully elucidate the underlying mechanisms of combination therapy, achieve optimal delivery systems and extensively evaluate efficacy and safety.

\section{Acknowledgments}

We thank Dr Xuyang Hou from Central South University for literature screening support.

\section{Funding}

This work was funded by the Hunan Province Education Project (20A369).

\section{Disclosure}

The authors declare that there are competing interests.

\section{References}

1. Bray F, Ferlay J, Soerjomataram I, Siegel RL, Torre LA, Jemal A. Global cancer statistics 2018: GLOBOCAN estimates of incidence and mortality worldwide for 36 cancers in 185 countries. CA Cancer J Clin. 2018;68(6):394-424. doi:10.3322/caac.21492

2. American Cancer Society. Cancer Facts \& Figures 2015. American Cancer Society; 2015.

3. Vansteenkiste J, Crinò L, Dooms C, et al. 2nd ESMO Consensus Conference on Lung Cancer: early-stage non-small-cell lung cancer consensus on diagnosis, treatment and follow-up. Ann Oncol. 2014;25(8):1462-1474. doi:10.1093/annonc/mdu089

4. Tsao AS, Scagliotti GV, Bunn PA, et al. Scientific advances in lung cancer 2015. J Thorac Oncol. 2016;11(5):613-638. doi:10.1016/j.jtho.2016.03.012

5. Gettinger SN, Horn L, Gandhi L, et al. Overall survival and longterm safety of nivolumab (anti-programmed death 1 antibody, BMS-936558, ONO-4538) in patients with previously treated advanced non-small-cell lung cancer. J Clin Oncol. 2015;33 (18):2004. doi:10.1200/JCO.2014.58.3708

6. Ammon HP, Wahl MA. Pharmacology of Curcuma longa. Planta Medica. 1991;57(1):1-7. doi:10.1055/s-2006-960004

7. Lelli D, Sahebkar A, Johnston TP, Pedone C. Curcumin use in pulmonary diseases: state of the art and future perspectives. Pharmacol Res. 2017;115:133-148. doi:10.1016/j.phrs.2016.11.017

8. Cohn L, Elias JA, Chupp GL. Asthma: mechanisms of disease persistence and progression. Апnи Rev Immunol. 2004;22:789-815. doi:10.1146/annurev.immunol.22.012703.104716

9. Xu F, Diao R, Liu J, Kang Y, Wang X, Shi L. Curcumin attenuates staphylococcus aureus-induced acute lung injury. Clin Respir J. 2015;9(1):87-97. doi:10.1111/crj.12113

10. Durgaprasad S, Pai CG, Alvres JF. A pilot study of the antioxidant effect of curcumin in tropical pancreatitis. Indian $J$ Med Res. 2005;122(4):315.

11. Shehzad A, Lee YS. Molecular mechanisms of curcumin action: signal transduction. Biofactors. 2013;39(1):27-36. doi:10.1002/ biof. 1065
12. Lelli D, Pedone C, Majeed M, Sahebkar A. Curcumin and lung cancer: the role of microRNAs. Current Pharmaceutical Design. 2017;23(23):3440-3444. doi:10.2174/1381612823666170109144 818

13. Mehta HJ, Patel V, Sadikot RT. Curcumin and lung cancer-a review. Target Oncol. 2014;9(4):295-310. doi:10.1007/s11523014-0321-1

14. Luthra PM, Lal N. Prospective of curcumin, a pleiotropic signalling molecule from Curcuma longa in the treatment of Glioblastoma. Eur J Med Chem. 2016;109:23-35. doi:10.1016/j. ejmech.2015.11.049

15. Feng T, Wei Y, Lee RJ, Zhao L. Liposomal curcumin and its application in cancer. Int $J$ Nanomedicine. 2017;12:6027. doi:10.2147/IJN.S132434

16. Lao CD, Ruffin MT, Normolle D, et al. Dose escalation of a curcuminoid formulation. BMC Complement Altern Med. 2006;6(1):1-4. doi:10.1186/1472-6882-6-10

17. Noureddin SA, El-Shishtawy RM, Al-Footy KO. Curcumin analogues and their hybrid molecules as multifunctional drugs. Eur J Med Chem. 2019;182:111631. doi:10.1016/j.ejmech.2019.111631

18. Golombek SK, May JN, Theek B, et al. Tumor targeting via EPR: strategies to enhance patient responses. Adv Drug Deliv Rev. 2018;130:17-38. doi:10.1016/j.addr.2018.07.007

19. Zhang B, Hu Y, Pang Z. Modulating the tumor microenvironment to enhance tumor nanomedicine delivery. Front Pharmacol. 2017;8:952. doi:10.3389/fphar.2017.00952

20. Chauhan VP, Stylianopoulos T, Martin JD, et al. Normalization of tumour blood vessels improves the delivery of nanomedicines in a size-dependent manner. Nat Nanotechnol. 2012;7(6):383. doi:10. 1038/nnano.2012.45

21. Zhao M, van Straten D, Broekman ML, Préat V, Schiffelers RM. Nanocarrier-based drug combination therapy for glioblastoma. Theranostics. 2020;10(3):1355. doi:10.7150/thno.38147

22. Wang J, Wang X, Wang X, et al. Curcumin inhibits the growth via Wnt/beta-catenin pathway in non-small-cell lung cancer cells. Eur Rev Med Pharmacol Sci. 2018;22(21):7492-7499. doi:10.26355/ eurrev_201811_16290

23. Li F, Chen X, Xu B, Zhou H. Curcumin induces p53-independent necrosis in $\mathrm{H} 1299$ cells via a mitochondria-associated pathway. Mol Med Rep. 2015;12(5):7806-7814. doi:10.3892/mmr.2015.4395

24. Shehzad A, Lee J, Huh TL, Lee YS. Curcumin induces apoptosis in human colorectal carcinoma (HCT-15) cells by regulating expression of Prp4 and p53. Mol Cells. 2013;35(6):526-532. doi:10.1007/s10059-013-0038-5

25. Lev-Ari S, Starr A, Katzburg S, et al. Curcumin induces apoptosis and inhibits growth of orthotopic human non-small cell lung cancer xenografts. $J$ Nutr Biochem. 2014;25(8):843-850. doi:10. 1016/j.jnutbio.2014.03.014

26. Ye M, Zhang J, Zhang J, Miao Q, Yao L, Zhang J. Curcumin promotes apoptosis by activating the p53-miR-192-5p/215-XIAP pathway in non-small cell lung cancer. Cancer Lett. 2015;357 (1):196-205. doi:10.1016/j.canlet.2014.11.028

27. Endo H, Inoue I, Masunaka K, Tanaka M, Yano M. Curcumin induces apoptosis in lung cancer cells by 14-3-3 protein-mediated activation of Bad. Biosci Biotechnol Biochem. 2020;84 (12):2440-2447. doi:10.1080/09168451.2020.1808443

28. Zhou GZ, Li AF, Sun YH, Sun GC. A novel synthetic curcumin derivative MHMM-41 induces ROS-mediated apoptosis and migration blocking of human lung cancer cells A549. Biomed Pharmacother. 2018;103:391-398. doi:10.1016/j.biopha.2018. 04.086

29. Jin H, Qiao F, Wang Y, Xu Y, Shang Y. Curcumin inhibits cell proliferation and induces apoptosis of human non-small cell lung cancer cells through the upregulation of miR-192-5p and suppression of PI3K/Akt signaling pathway. Oncol Rep. 2015;34 (5):2782-2789. doi:10.3892/or.2015.4258 
30. Xu X, Zhu Y. Curcumin inhibits human non-small cell lung cancer xenografts by targeting STAT3 pathway. Am J Transl Res. 2017;9(8):3633.

31. Pongrakhananon V, Nimmannit U, Luanpitpong S, Rojanasakul Y, Chanvorachote P. Curcumin sensitizes non-small cell lung cancer cell anoikis through reactive oxygen species-mediated Bcl-2 downregulation. Apoptosis. 2010;15 (5):574-585. doi:10.1007/s10495-010-0461-4

32. Chiang I, Wang WS, Liu HC, Yang ST, Tang NY, Chung JG. Curcumin alters gene expression-associated DNA damage, cell cycle, cell survival and cell migration and invasion in NCI-H460 human lung cancer cells in vitro. Oncol Rep. 2015;34 (4):1853-1874. doi:10.3892/or.2015.4159

33. Shen S, Kepp O, Kroemer G. The end of autophagic cell death? Autophagy. 2012;8:1-3. doi:10.4161/auto.8.1.16618

34. Xiao K, Jiang J, Guan C, et al. Curcumin induces autophagy via activating the AMPK signaling pathway in lung adenocarcinoma cells. J Pharmacol Sci. 2013;123:13085FP. doi:10.1254/jphs.13085fp

35. Lee M, Kim KS, Fukushi A, Kim DH, Kim CH, Lee YC. Transcriptional activation of human GD3 synthase (hST8Sia I) gene in curcumin-induced autophagy in A549 human lung carcinoma cells. Int J Mol Sci. 2018;19(7):1943. doi:10.3390/ijms19071943

36. Klionsky DJ, Abdelmohsen K, Abe A, et al. Guidelines for the use and interpretation of assays for monitoring autophagy. Autophagy. 2016;12(1):1-222.

37. Chen HW, Lee JY, Huang JY, et al. Curcumin inhibits lung cancer cell invasion and metastasis through the tumor suppressor HLJ1. Cancer Res. 2008;68(18):7428-7438. doi:10.1158/0008-5472. CAN-07-6734

38. Lu Y, Wei C, Xi Z. Curcumin suppresses proliferation and invasion in non-small cell lung cancer by modulation of MTA1mediated Wnt/ $\beta$-catenin pathway. In Vitro Cell Dev Biol Anim. 2014;50(9):840-850. doi:10.1007/s11626-014-9779-5

39. Chen QY, Jiao DM, Yao QH, et al. Expression analysis of Cdc42 in lung cancer and modulation of its expression by curcumin in lung cancer cell lines. Int $J$ Oncol. 2012;40(5):1561-1568. doi:10.3892/ijo.2012.1336

40. Zucker S, Vacirca J. Role of matrix metalloproteinases (MMPs) in colorectal cancer. Cancer Metastasis Rev. 2004;23(1-2):101-117. doi:10.1023/A:1025867130437

41. Chen QY, Zheng Y, Jiao DM, et al. Curcumin inhibits lung cancer cell migration and invasion through Rac1-dependent signaling pathway. J Nutr Biochem. 2014;25(2):177-185. doi:10.1016/j. jnutbio.2013.10.004

42. Fan Z, Duan X, Cai H, et al. Curcumin inhibits the invasion of lung cancer cells by modulating the $\mathrm{PKC} \alpha / \mathrm{Nox}-2 / \mathrm{ROS} / \mathrm{ATF}-2 /$ MMP-9 signaling pathway. Oncol Rep. 2015;34(2):691-698. doi:10.3892/or.2015.4044

43. Lin SS, Lai KC, Hsu SC, et al. Curcumin inhibits the migration and invasion of human A549 lung cancer cells through the inhibition of matrix metalloproteinase-2 and-9 and Vascular Endothelial Growth Factor (VEGF). Cancer Lett. 2009;285(2):127-133. doi:10.1016/j.canlet.2009.04.037

44. Tsai JR, Liu PL, Chen YH, et al. Curcumin inhibits non-small cell lung cancer cells metastasis through the adiponectin/NF- $\kappa \mathrm{b} /$ MMPs signaling pathway. PLoS One. 2015;10(12):e0144462. doi:10.1371/journal.pone.0144462

45. Zhan J, Jiao D, Wang Y, et al. Integrated micro RNA and gene expression profiling reveals the crucial mi RNA $\mathrm{s}$ in curcumin anti-lung cancer cell invasion. Thorac Cancer. 2017;8 (5):461-470. doi:10.1111/1759-7714.12467

46. Wang N, Feng T, Liu X, Liu Q. Curcumin inhibits migration and invasion of non-small cell lung cancer cells through up-regulation of miR-206 and suppression of PI3K/AKT/mTOR signaling pathway. Acta pharmaceutica. 2020;70(3):399-409. doi:10.2478/ acph-2020-0029
47. Zhang X, Zhang C, Ren Z, et al. Curcumin affects gastric cancer cell migration, invasion and cytoskeletal remodeling through Gli1- $\beta$-catenin. Cancer Manag Res. 2020;12:3795-3806. doi:10.2147/CMAR.S244384

48. Salehi M, Movahedpour A, Tayarani A, et al. Therapeutic potentials of curcumin in the treatment of non-small-cell lung carcinoma. Phytother Res. 2020;34(10):2557-2576. doi:10.1002/ ptr.6704

49. Jiao D, Wang J, Lu W, et al. Curcumin inhibited HGF-induced EMT and angiogenesis through regulating c-Met dependent PI3K/ Akt/mTOR signaling pathways in lung cancer. Mol Ther Oncolytics. 2016;3:16018. doi:10.1038/mto.2016.18

50. Yan L. Dietary supplementation with curcumin enhances metastatic growth of Lewis lung carcinoma in mice. Int $J$ Cancer. 2013;132(2):269-275. doi:10.1002/ijc.27683

51. Reck M, Popat S, Reinmuth N, De Ruysscher D, Kerr K, Peters S. Metastatic non-small-cell lung cancer (NSCLC): ESMO Clinical Practice Guidelines for diagnosis, treatment and follow-up. Ann Oncol. 2014;25(suppl_3):iii27-iii39.

52. Giaccone G, Splinter TA, Debruyne C, et al. Randomized study of paclitaxel-cisplatin versus cisplatin-teniposide in patients with advanced non-small-cell lung cancer. The European Organization for Research and Treatment of Cancer Lung Cancer Cooperative Group. J Clin Oncol. 1998;16 (6):2133-2141. doi:10.1200/JCO.1998.16.6.2133

53. Lin JJ, Shaw AT. Resisting resistance: targeted therapies in lung cancer. Trends Cancer. 2016;2(7):350-364. doi:10.1016/j.trecan. 2016.05.010

54. Zhang J, Zhang $\mathrm{T}$, Ti X, et al. Curcumin promotes apoptosis in A549/DDP multidrug-resistant human lung adenocarcinoma cells through an miRNA signaling pathway. Biochem Biophys Res Commun. 2010;399(1):1-6. doi:10.1016/j.bbrc.2010.07.013

55. Kim KC, Baek SH, Lee C. Curcumin-induced downregulation of Axl receptor tyrosine kinase inhibits cell proliferation and circumvents chemoresistance in non-small lung cancer cells. Int J Oncol. 2015;47(6):2296-2303. doi:10.3892/ijo.2015.3216

56. Chen P, Huang H-P, Wang Y, et al. Curcumin overcome primary gefitinib resistance in non-small-cell lung cancer cells through inducing autophagy-related cell death. J Exp Clin Cancer Res. 2019;38(1):254. doi:10.1186/s13046-019-1234-8

57. Hanahan D, Weinberg RA. Hallmarks of cancer: the next generation. cell. 2011;144(5):646-674. doi:10.1016/j.cell.2011.02.013

58. Prager BC, Xie Q, Bao S, Rich JN. Cancer stem cells: the architects of the tumor ecosystem. Cell Stem Cell. 2019;24 (1):41-53. doi:10.1016/j.stem.2018.12.009

59. Yen H-Y, Tsao C-W, Lin Y-W, Kuo -C-C, Tsao C-H, Liu C-Y. Regulation of carcinogenesis and modulation through Wnt/ $\beta$ catenin signaling by curcumin in an ovarian cancer cell line. Sci Rep. 2019;9(1):1-14. doi:10.1038/s41598-019-53509-3

60. Mirza S, Vasaiya A, Vora H, Jain N, Rawal R. Curcumin targets circulating cancer stem cells by inhibiting self-renewal efficacy in non-small cell lung carcinoma. Curr Med Chem Anticancer Agents. 2016;17(6):859.

61. Puliyappadamba VT, Thulasidasan AKT, Vijayakurup V, Antony J, Anto RJ. Curcumin inhibits B[a]PDE-induced procarcinogenic signals in lung cancer cells, and curbs $\mathrm{B}[\mathrm{a}] \mathrm{P}$-induced mutagenesis and lung carcinogenesis. Biofactors. 2015;41 (6):431-442. doi:10.1002/biof.1244

62. Moghaddam SJ, Barta P, Mirabolfathinejad SG, et al. Curcumin inhibits COPD-like airway inflammation and lung cancer progression in mice. Carcinogenesis. 2009;30(11):1949-1956. doi:10. 1093/carcin/bgp229

63. Zhou S, Li J, Xu H, et al. Liposomal curcumin alters chemosensitivity of breast cancer cells to Adriamycin via regulating microRNA expression. Gene. 2017;622:1-12. doi:10.1016/j. gene.2017.04.026 
64. S Darvesh A, B Aggarwal B, Bishayee A. Curcumin and liver cancer: a review. Curr Pharm Biotechnol. 2012;13(1):218-228. doi:10.2174/138920112798868791

65. Zhang T, Chen Y, Ge Y, Hu Y, Li M, Jin Y. Inhalation treatment of primary lung cancer using liposomal curcumin dry powder inhalers. Acta Pharmaceutica Sinica B. 2018;8(3):440-448. doi:10.1016/j.apsb.2018.03.004

66. Zhu WT, Liu SY, Wu L, et al. Delivery of curcumin by directed self-assembled micelles enhances therapeutic treatment of non-small-cell lung cancer. Int J Nanomedicine. 2017;12:2621. doi:10.2147/IJN.S128921

67. Wei X, Du ZY, Cui XX, et al. Effects of cyclohexanone analogues of curcumin on growth, apoptosis and NF- $\kappa$ B activity in PC-3 human prostate cancer cells. Oncol Lett. 2012;4(2):279-284. doi: $10.3892 / \mathrm{ol} .2012 .710$

68. He K, Tang M. Safety of novel liposomal drugs for cancer treatment: advances and prospects. Chem Biol Interact. 2018;295:13-19. doi:10.1016/j.cbi.2017.09.006

69. Liu Y, Gao D, Zhang X, et al. Antitumor drug effect of betulinic acid mediated by polyethylene glycol modified liposomes. Mater Sci Eng C. 2016;64:124-132. doi:10.1016/j.msec.2016.03.080

70. Guo XX, He W, Zhang XJ, Hu XM. Cytotoxicity of cationic liposomes coated by $\mathrm{N}$-trimethyl chitosan and their in vivo tumor angiogenesis targeting containing doxorubicin. $J$ Appl Polym Sci. 2013;128(1):21-27. doi:10.1002/app.37701

71. Pandey H, Rani R, Agarwal V. Liposome and their applications in cancer therapy. Brazilian Arch Biol Technol. 2016;59. doi:10. 1590/1678-4324-2016150477

72. Marzbali MY, Khosroushahi AY. Polymeric micelles as mighty nanocarriers for cancer gene therapy: a review. Cancer Chemother Pharmacol. 2017;79(4):637-649. doi:10.1007/s002 80-017-3273-1

73. Patil S, Choudhary B, Rathore A, Roy K, Mahadik K. Enhanced oral bioavailability and anticancer activity of novel curcumin loaded mixed micelles in human lung cancer cells. Phytomedicine. 2015;22(12):1103-1111. doi:10.1016/j.phymed. 2015.08.006

74. Son KH, Hong JH, Lee JW. Carbon nanotubes as cancer therapeutic carriers and mediators. Int J Nanomedicine. 2016;11:5163. doi:10.2147/IJN.S112660

75. Singh N, Sachdev A, Gopinath P. Polysaccharide functionalized single walled carbon nanotubes as nanocarriers for delivery of curcumin in lung cancer cells. J Nanosci Nanotechnol. 2018;18 (3):1534-1541. doi:10.1166/jnn.2018.14222

76. Fiegel V, Harlepp S, Begin-Colin S, Begin D, Mertz D. Design of protein-coated carbon nanotubes loaded with hydrophobic drugs through sacrificial templating of mesoporous silica shells. Chem Eur J. 2018;24(18):4662-4670. doi:10.1002/chem.201705845

77. Li H, Zhang N, Hao Y, et al. Formulation of curcumin delivery with functionalized single-walled carbon nanotubes: characteristics and anticancer effects in vitro. Drug Deliv. 2014;21 (5):379-387. doi:10.3109/10717544.2013.848246

78. Ganesan P, Ramalingam P, Karthivashan G, Ko YT, Choi D-K. Recent developments in solid lipid nanoparticle and surface-modified solid lipid nanoparticle delivery systems for oral delivery of phyto-bioactive compounds in various chronic diseases. Int $J$ Nanomed. 2018;13:1569. doi:10.2147/IJN. S155593

79. Baek JS, Cho CW. A multifunctional lipid nanoparticle for co-delivery of paclitaxel and curcumin for targeted delivery and enhanced cytotoxicity in multidrug resistant breast cancer cells. Oncotarget. 2017;8(18):30369. doi:10.18632/oncotarget.16153

80. Guorgui J, Wang R, Mattheolabakis G, Mackenzie GG. Curcumin formulated in solid lipid nanoparticles has enhanced efficacy in Hodgkin's lymphoma in mice. Arch Biochem Biophys. 2018;648:12-19. doi:10.1016/j.abb.2018.04.012
81. Wang P, Zhang L, Peng H, Li Y, Xiong J, Xu Z. The formulation and delivery of curcumin with solid lipid nanoparticles for the treatment of on non-small cell lung cancer both in vitro and in vivo. Mater Sci Eng C. 2013;33(8):4802-4808. doi:10.1016/j. msec.2013.07.047

82. Wang L, Du J, Zhou Y, Wang Y. Safety of nanosuspensions in drug delivery. Nanomedicine. 2017;13(2):455-469. doi:10.1016/j. nano.2016.08.007

83. Hong J, Liu Y, Xiao Y, et al. High drug payload curcumin nanosuspensions stabilized by mPEG-DSPE and SPC: in vitro and in vivo evaluation. Drug Deliv. 2017;24(1):109-120. doi:10.1080/10717544.2016.1233589

84. Aditya N, Yang H, Kim S, Ko S. Fabrication of amorphous curcumin nanosuspensions using $\beta$-lactoglobulin to enhance solubility, stability, and bioavailability. Colloids Surf B Biointerfaces. 2015;127:114-121. doi:10.1016/j.colsurfb.2015.01.027

85. Wang Y, Wang C, Zhao J, Ding Y, Li L. A cost-effective method to prepare curcumin nanosuspensions with enhanced oral bioavailability. $J$ Colloid Interface Sci. 2017;485:91-98. doi:10.1016/j.jcis.2016.09.003

86. Singh Y, Meher JG, Raval K, et al. Nanoemulsion: concepts, development and applications in drug delivery. $J$ Control Release. 2017;252:28-49. doi:10.1016/j.jconrel.2017.03.008

87. Wan K, Sun L, Hu X, et al. Novel nanoemulsion based lipid nanosystems for favorable in vitro and in vivo characteristics of curcumin. Int J Pharm. 2016;504(1-2):80-88. doi:10.1016/j. ijpharm.2016.03.055

88. Chang H-B, Chen B-H. Inhibition of lung cancer cells A549 and H460 by curcuminoid extracts and nanoemulsions prepared from Curcuma longa Linnaeus. Int J Nanomedicine. 2015;10:5059. doi:10.2147/IJN.S87225

89. Baghbani F, Moztarzadeh F. Bypassing multidrug resistant ovarian cancer using ultrasound responsive doxorubicin/curcumin co-deliver alginate nanodroplets. Colloids Surf B Biointerfaces. 2017;153:132-140. doi:10.1016/j.colsurfb.2017.01.051

90. Guerrero S, Inostroza-Riquelme M, Contreras-Orellana P, et al. Curcumin-loaded nanoemulsion: a new safe and effective formulation to prevent tumor reincidence and metastasis. Nanoscale. 2018;10(47):22612-22622. doi:10.1039/C8NR06173D

91. Marote A, Teixeira FG, Mendes-Pinheiro B, Salgado AJ. MSCsderived exosomes: cell-secreted nanovesicles with regenerative potential. Front Pharmacol. 2016;7:231. doi:10.3389/fphar.20 16.00231

92. Cheng L, Zhang K, Wu S, Cui M, Xu T. Focus on mesenchymal stem cell-derived exosomes: opportunities and challenges in cell-free therapy focus on mesenchymal stem cell-derived exosomes: opportunities and challenges in cell-free therapy. Focus. 2021.

93. Aqil F, Munagala R, Jeyabalan J, Agrawal AK, Gupta R. Exosomes for the enhanced tissue bioavailability and efficacy of curcumin. AAPS J. 2017;19(6):1691-1702. doi:10.1208/s12248017-0154-9

94. Dance-Barnes ST, Kock ND, Moore JE, et al. Lung tumor promotion by curcumin. Carcinogenesis. 2009;30(6):1016-1023. doi:10.1093/carcin/bgp082

95. Su CC, Yang JS, Lu CC, et al. Curcumin inhibits human lung large cell carcinoma cancer tumour growth in a murine xenograft model. Phytother Res. 2010;24(2):189-192. doi:10.1002/ptr.2905

96. Tung CL, Jian YJ, Chen JC, et al. Curcumin downregulates p38 MAPK-dependent X-ray repair cross-complement group 1 (XRCC1) expression to enhance cisplatin-induced cytotoxicity in human lung cancer cells. Naunyn Schmiedebergs Arch Pharmacol. 2016;389(6):657-666. doi:10.1007/s00210-016-1235-5

97. Zhang W, Shi H, Chen C, et al. Curcumin enhances cisplatin sensitivity of human NSCLC cell lines through influencing Cu-Sp1-CTR1 regulatory loop. Phytomedicine. 2018;48:51-61. doi:10.1016/j.phymed.2018.04.058 
98. Baharuddin P, Satar N, Fakiruddin KS, et al. Curcumin improves the efficacy of cisplatin by targeting cancer stem-like cells through p21 and cyclin D1-mediated tumour cell inhibition in non-small cell lung cancer cell lines. Oncol Rep. 2016;35 (1):13-25. doi:10.3892/or.2015.4371

99. Kang JH, Kang HS, Kim IK, et al. Curcumin sensitizes human lung cancer cells to apoptosis and metastasis synergistically combined with carboplatin. Exp Biol Med. 2015;240(11):1416-1425. doi: $10.1177 / 1535370215571881$

100. Yin H, Guo R, Xu Y, et al. Synergistic antitumor efficiency of docetaxel and curcumin against lung cancer. Acta Biochim Biophys Sin. 2012;44(2):147-153. doi:10.1093/abbs/gmr106

101. Saghatelyan T, Tananyan A, Janoyan N, et al. Efficacy and safety of curcumin in combination with paclitaxel in patients with advanced, metastatic breast cancer: a comparative, randomized, double-blind, placebo-controlled clinical trial. Phytomedicine. 2020;70:153218. doi:10.1016/j.phymed.2020.153218

102. Ko JC, Tsai MS, Weng SH, Kuo YH, Chiu YF, Lin YW. Curcumin enhances the mitomycin $\mathrm{C}$-induced cytotoxicity via downregulation of MKK1/2-ERK1/2-mediated Rad51 expression in non-small cell lung cancer cells. Toxicol Appl Pharmacol. 2011;255(3):327-338. doi:10.1016/j.taap.2011.07.012

103. Chen H, Chen L, Wang L, et al. Synergistic effect of fenretinide and curcumin for treatment of non-small cell lung cancer. Cancer Biology \& Therapy. 2016;17(10):1022-1029. doi:10.1080/ 15384047.2016.1219810

104. Man S, Zhang L, Cui J, Yang L, Ma L, Gao W. Curcumin enhances the anti-cancer effects of Paris Saponin II in lung cancer cells. Cell Proliferation. 2018;51(4):e12458. doi:10.1111/cpr.12458

105. Zhou DH, Wang X, Yang $M$, Shi X, Huang W, Feng Q. Combination of low concentration of $(-)$-epigallocatechin gallate (EGCG) and curcumin strongly suppresses the growth of nonsmall cell lung cancer in vitro and in vivo through causing cell cycle arrest. Int J Mol Sci. 2013;14(6):12023-12036. doi:10.3390/ ijms140612023

106. Hirsch FR, Scagliotti GV, Mulshine JL, et al. Lung cancer: current therapies and new targeted treatments. Lancet. 2017;389 (10066):299-311. doi:10.1016/S0140-6736(16)30958-8

107. Byers LA, Diao L, Wang J, et al. An epithelial-mesenchymal transition gene signature predicts resistance to EGFR and PI3K inhibitors and identifies Axl as a therapeutic target for overcoming EGFR inhibitor resistance. Clin Cancer Res. 2013;19 (1):279-290. doi:10.1158/1078-0432.CCR-12-1558

108. Yamauchi Y, Izumi Y, Yamamoto J, Nomori H. Coadministration of erlotinib and curcumin augmentatively reduces cell viability in lung cancer cells. Phytother Res. 2014;28(5):728-735. doi: $10.1002 /$ ptr.5056

109. Lin HP, Kuo LK, Chuu CP. Combined treatment of curcumin and small molecule inhibitors suppresses proliferation of A549 and H1299 human non-small-cell lung cancer cells. Phytother Res. 2012;26(1):122-126. doi:10.1002/ptr.3523

110. Hu Q, Sun W, Wang C, Gu Z. Recent advances of cocktail chemotherapy by combination drug delivery systems. Adv Drug Deliv Rev. 2016;98:19-34. doi:10.1016/j.addr.2015.10.022
111. Wang BL, Shen YM, Zhang QW, et al. Codelivery of curcumin and doxorubicin by MPEG-PCL results in improved efficacy of systemically administered chemotherapy in mice with lung cancer. Int J Nanomedicine. 2013;8:3521

112. Lee WH, Loo CY, Traini D, Young PM. Development and evaluation of paclitaxel and curcumin dry powder for inhalation lung cancer treatment. Pharmaceutics. 2020;13(1):9. doi:10.3390/ pharmaceutics 13010009

113. Jiang K, Shen M, Xu W. Arginine, glycine, aspartic acid peptide-modified paclitaxel and curcumin co-loaded liposome for the treatment of lung cancer: in vitro/vivo evaluation. Int J Nanomedicine. 2018;13:2561. doi:10.2147/IJN.S157746

114. Rudnik LAC, Farago PV, Manfron Budel J, et al. Co-loaded curcumin and methotrexate nanocapsules enhance cytotoxicity against non-small-cell lung cancer cells. Molecules. 2020;25 (8):1913. doi:10.3390/molecules25081913

115. Hong Y, Che S, Hui B, Wang X, Zhang X, Ma H. Combination therapy of lung cancer using layer-by-layer cisplatin prodrug and curcumin co-encapsulated nanomedicine. Drug Des Devel Ther. 2020;14:2263-2274. doi:10.2147/DDDT.S241291

116. Jyoti K, Pandey RS, Kush P, Kaushik D, Jain UK, Madan J. Inhalable bioresponsive chitosan microspheres of doxorubicin and soluble curcumin augmented drug delivery in lung cancer cells. Int J Biol Macromol. 2017;98:50-58. doi:10.1016/j. ijbiomac.2017.01.109

117. Huang Z, Zhou L, Chen Z, Nice EC, Huang C. Stress management by autophagy: implications for chemoresistance. Int J Cancer. 2016;139(1):23-32. doi:10.1002/ijc.29990

118. Nishiguchi $\mathrm{Y}$, Oue N, Fujiwara-Tani R, et al. Role of metastasis-related genes in cisplatin chemoresistance in gastric cancer. Int J Mol Sci. 2020;21(1):254. doi:10.3390/ijms21010254

119. Jia J, Zhu F, Ma X, Cao ZW, Li YX, Chen YZ. Mechanisms of drug combinations: interaction and network perspectives. Nat Rev Drug Discov. 2009;8(2):111-128.

120. Noh J, Kwon B, Han E, et al. Amplification of oxidative stress by a dual stimuli-responsive hybrid drug enhances cancer cell death. Nat Commun. 2015;6(1):1-9. doi:10.1038/ncomms7907

121. Bozic I, Reiter JG, Allen B, et al. Evolutionary dynamics of cancer in response to targeted combination therapy. elife. 2013;2:e00747. doi:10.7554/eLife.00747

122. Setyawati MI, Tay CY, Docter D, Stauber RH, Leong DT. Understanding and exploiting nanoparticles' intimacy with the blood vessel and blood. Chem Soc Rev. 2015;44(22):8174-8199. doi: $10.1039 / \mathrm{C} 5 \mathrm{CS} 00499 \mathrm{C}$

123. Rajani C, Borisa $\mathrm{P}$, Karanwad $\mathrm{T}$, et al. Cancer-targeted chemotherapy: emerging role of the folate anchored dendrimer as drug delivery nanocarrier. In: Pharmaceutical Applications of Dendrimers. Elsevier; 2020:151-198.

124. Liu C, Cui Z, Zhang X, Mao S. Nanobiomaterials in drug delivery: designing strategies and critical concepts for their potential clinical applications. In: Nanobiomaterial Engineering. Springer; 2020:253-274.

\section{Publish your work in this journal}

Drug Design, Development and Therapy is an international, peerreviewed open-access journal that spans the spectrum of drug design and development through to clinical applications. Clinical outcomes, patient safety, and programs for the development and effective, safe, and sustained use of medicines are a feature of the journal, which has also been accepted for indexing on PubMed Central. The manuscript management system is completely online and includes a very quick and fair peer-review system, which is all easy to use. Visit http://www. dovepress.com/testimonials.php to read real quotes from published authors. 